\title{
The Politics of Alcohol Policy in Nigeria: A Critical Analysis of how and why Brewers use Strategic Ambiguity to Supplant Policy Initiatives
}

Emeka W. Dumbili

Brunel University, London (emeka.dumbili@brunel.ac.uk; favourfredy@yahoo.com)

\begin{abstract}
The global call by the World Health Assembly (WHA) to control the rising alcohol-related problems caused by harmful consumption through policy became necessary in 2005 due to the recognition of the fact that many countries did not have alcohol policies. This gave rise to the adoption of a ten-point policy strategy by the World Health Organization (WHO) Member States in 2010. Against this backdrop, many countries adopted alcohol policies to reduce harmful alcohol consumption. Nigeria was one of the WHO Member Countries that adopted the resolution. Nigeria is among the 30 countries with the highest per capita consumption and alcohol-related problems, yet has not formulated alcohol policy to date. This paper draws on Eisenberg's Strategic Ambiguity Model to explore the role of brewers in supplanting alcohol policy initiatives in Nigeria. It argues that the leading alcohol producers in Nigeria have been the main reason alcohol policies have not been formulated. The article focuses on why their campaigns for responsible drinking, promotions, sponsorships and 'strategic social responsibilities' may have increased since the WHA made the call and the WHO adopted the resolution in 2010. It concludes by arguing that there is an urgent need to formulate policies drawing from the WHO resolution to curtail the activities of these brewers and reduce harmful consumption.
\end{abstract}

Keywords Alcohol advertising, Alcohol Policy, Alcohol-related problems, Brewers, ICAP, Nigeria, Strategic Ambiguity 


\section{Introduction}

The rising global alcohol consumption and alcohol-related morbidity and mortality necessitated the WHA in 2005 to call for effective policies to curb alcohol misuse (WHO, 2005). The call was directed at the WHO to join hands with member countries to facilitate policy implementation channelled towards the reduction of alcohol misuse and related problems. The World Health Assembly on 24 May 2008 adopted a resolution that: 'calls for the development by 2010 of a draft global strategy to reduce the harmful use of alcohol based on available evidence and existing best practices, and that addresses relevant policy options' (WHO, 2009: 1). In May 2010, the 193 delegates to the Sixty-Third WHA reached an agreement to reduce harmful alcohol use (and its related problems) based on the WHA 2008 draft strategies and subsequently adopted the resolution WHA63.13 (Chick, 2011; Poznyak, 2010). The resolution's main thrusts include inter alia: commitment of leaders to the policy, control of marketing and availability of alcohol, pricing policies aimed at reducing purchase.

Prior to this, there had been many programmes formulated by the WHO to either reduce or control harmful use of alcohol and drug globally. Between 1979 and 2010, the WHA and WHO received eight Reports aimed at either raising awareness or reduction of alcohol-related harms. Following the clarion call by the WHA in 2005, the drafting of 10 strategies in 2008 and the adoption of the resolution in 2010, many countries have responded by adopting policies to reduce harmful use of alcohol globally. Some African countries such as South Africa, Lesotho, Botswana, Malawi, Uganda and Kenya have responded by drafting policies to regulate alcohol harm in their countries (Parry, 2010; Bakke and Endal, 2010; Pitso and Obot, 2011; Obot 2012). South Africa's policies such as National Liquor Bill, the policy that restricted adverts and sales of alcohol, etc. have begun to yield results while Botswana recently took further steps by increasing the price of alcohol to help control availability (Parry, 2010; Pitso and Obot, 2011).

Nigeria is a member of the WHO and was one of the 193 delegates that adopted the 2010 resolution to reduce alcohol-related problems through policies. To date, however, Nigeria has eschewed any meaningful action towards formulating and implementing policies 
despite convincing evidence of the harm excess alcohol consumption adds to the burden of disease, injuries and death in Nigeria (WHO, 2004). In fact, the WHO (2009) stated that Nigeria consumed 10.57 Litres of alcohol per head of the population and these figures were higher than what the USA (8.6 Litres) consumed. This can be authenticated by Gureje et al's (2007: 7) finding: 'that alcohol is the most used drug in Nigeria' and that 'heavy episodic drinking, rather than moderate drinking is common among users of alcohol in Nigeria'. To date, there is no legal document in the form of policy in Nigeria to respond to increasing alcohol-related problems (Obot, 2007). This neglect has a long history according to Anumonye et al. (1977: 27):

So far alcohol has not received the attention it deserves in Nigeria. It is increasingly abused. This abuse will become a serious problem within the next few years since: the prohibition on the formally illicit locally brewed gin has been lifted... beer breweries proliferated apparently for political purposes.... Local distilling of gin has recently received government blessing; bottling of imported spirits is very common now; the indigenous palm wine is gradually disappearing from the cities where more potent alcohol is being used.

Successive Nigerian governments have continued to shun the regulation of harmful alcohol through policy as it has done in other sectors of the economy (Oluwaniyi, 2010). Globally, Nigeria is one of the 30 countries with highest per capita alcohol consumption and in Africa: Nigeria ranks second after Uganda due to myriad of reasons (WHO, 2004). One of the key reasons is because alcohol is the commonest drug consumed in the country due to unrestricted availability (Gureje et al., 2007). Uganda has begun to implement policies to control alcohol consumption, but in Nigeria alcohol consumption is increasing (Chikere and Mayowa, 2011) without a corresponding policy to control the harmful use. Yearly, many lives are lost through the road traffic accident linked to harmful alcohol use among drivers (Aworemi et al., 2010). In 2006, there were 4679 fatal accidents; in 2007, it rose to 8,477 traffic accidents, with 17, 794 injuries and 4673 deaths with many unrecorded figures from unreported cases (Toroyan, 2009). There are also increasing violence and disorder in different communities and families, and many are coming from higher schools linked to harmful alcohol use (Rotimi, 2005; Brisibe et al., 2012; Adewuya, 2005).

In a country with such significant alcohol-related problems, one might expect the formulation of appropriate policies by the government to reduce alcohol-related problems. 
However, the reverse appears to be the case in Nigeria which is arguably due to the fact that 'no single policy' exists. This is arguably linked to the activities of the alcohol producers who have been supplanting policy initiatives by campaigning for responsible drinking, thus, creating ambiguities in the economy. Their weapons are highly influential campaigns for responsible drinking (Vanguard, 2011), advertising, promotions, sponsorship of sports and other social events, etc. (De Bruijn, 2011; Obot and Ibanga, 2002). Some of these marketing activities have existed for many years but have become more aggressive since the WHA and WHO began the move to reduce alcohol related harms through policies. It can be argued that the primary motives of these brewers are to market their products, increase profit and maintain a good image at the expense of the policy as they do in other countries (Giesbrecht, 2004).

Taking a point of departure from Eisenberg's Strategic Ambiguity thesis, the locus of my argument in this article is that, in Nigeria, brewers have been employing strategic ambiguities to advance their mission of distracting the policy makers, health professionals and the populace from focusing on the reality of lack of policies to reduce the alcohol related harms, which their activities, are encouraging. The article is divided into four sections. The following part lays out the theoretical framework guiding the article, followed by the sections examining how brewers apply the model, arguably to achieve their purposes of hindering policy from being formulated and the conclusion.

\section{The Strategic Ambiguity Theory}

Eric Eisenberg, a communication expert was the first person to use the concept of Strategic Ambiguity (SA) in his seminal work- Ambiguity as Strategy in Organizational Communication (Eisenberg, 1984), where he posited that effective communication should not always be judged on openness or clarity of language because meaning is contextual. Therefore, 'people in organizations use ambiguity strategically to accomplish their goals' (Eisenberg, 1984: 228). Strategic Ambiguity, which is from the interactional communication paradigm is an organizational tool employed most times to achieve goals that clarity may not achieve (Eisenberg, 1984). Openness sometimes may be risky (Eisenberg and Witten 1987); therefore, organizations facing multiple goals can utilize ambiguous symbols or words to 
achieve these multiple goals because ambiguity is a product of language (Eisenberg, 1998). Clarity and ambiguity are two sides of the same coin: both are functional imperatives and none is the end in itself. As clarity is a feature of messages, so is ambiguity, which is advanced, via a combination of the source, message and receiver factors (Atkin et al., 2008). Therefore, it is often advanced as an effective tool of communication because: 'People in organizations confront multiple situational requirements, develop multiple and often conflicting goals, and respond with communicative strategies which do not always minimize ambiguity, but may nonetheless be effective' (Eisenberg, 1984: 228).

Eisenberg posited that, in organizing, clarity (openness) is an essential ingredient, but because organizations do not pursue unilateral goals, and are faced with tensions from within and without, manipulation of symbols to create ambiguity of communication becomes the best option in order to achieve these multiple goals even though he and other scholars acknowledged that this may not always be ethical. SA, therefore, is a purposeful, essential and effective means of communication.

Meanings are contextual and relative and are constituted by individuals. They are not 'inherent in any discourse' (Eisenberg, 1984: 229). For example, a word used in informal communication may not be understood the same way in a formal setting. This makes organizations to strategically select symbols loaded with ambiguities so as to achieve their goals, leaving individuals to decide based on their interpretations of the message. He said that SA is vital in an organization because it 'promotes unified diversity' (Eisenberg, 1984: 230) and helps in promoting the growth of many viewpoints because it leaves those who receive the message with multiple interpretations. Strategic Ambiguity in a nutshell is the employment of implicit language (with vague meaning) purposefully to achieve goals through the creation of multiple meanings or interpretations. It is functional, it is essential for organizations in turbulent environments where clarity may be risky and it achieves what clarity may not (Eisenberg, 1984) in most cases.

Several other scholars from diverse disciplines have employed this model to explore different studies. Ulmer and Sellnow (1997) posited that organizations use ambiguity to create a favourable image even though such activities may be considered to be unethical while Myers (1996) revealed that even in academic writing, ambiguity can sometimes be 
purposefully employed. Alesina and Holden (2008) also showed how candidates in an electioneering campaign can employ SA to score points and appeal to voters. This is done by announcing multiple policies than just a single one, thus creating escape routes in case the successful candidate did not pursue all.

Davenport and Leitch (2005) also revealed how SA applied to delegate authority in organizations while Riedel and Sass (2011) demonstrated how SA can be used in peace negotiation. In advertising, Pedersen (2002: 169) argues that advertisers create 'ambiguity within advertisements to gain double profit with consumers'. Agostinelli and colleague applying this model revealed that brewer-sponsored message is often ineffective in reducing alcohol-related problems because it is mostly designed to improve the brewer's image and sell their products (Agostinelli and Grube, 2002). Their findings further revealed that it permits 'liberal alcohol consumption even in a risky situation' (Agostinelli and Grube, 2002: 18), and this is because the messages are loaded with ambiguities. Other scholars have applied the SA model in their research (Zwarun and Farrar, 2005; Ulph and Ulph, 2001; Bernheim and Whinston, 1998; Ako, 2003; Burbank, 2006) to examine different phenomena and this shows its efficacy. The next section will demonstrate the role of brewers in alcohol policy in Nigeria through the use of different SAs, as effective measures to manipulate Nigerian society and achieve their multiple goals.

\section{Strategic Ambiguity as a Tool for Brewers in Nigeria}

\section{Strategic Ambiguity of 'Drink Responsibly' Campaign}

Globally, personal interest is known to engender or hinder policy formulation and implementation. This does not apply to alcohol policy alone, but includes other issues like wealth redistribution (Glennerster, 2012). In the area of alcohol policy, alcohol producers are known for hindering and rejecting a stringent regulatory policy that will control production and marketing due to economic interest (Miller et al., 2010). Some of their claims are that they, the producers, contribute to the economic growth (Room and Jernigan, 2000), therefore, restriction will engender a low sale which is tantamount to job loss. Another part of their claims is that advertising does not automatically predict increased 
drinking among children and adolescents as reported in Germany (Morgenstern et al., 2011). They prefer to promote a responsible drinking message- a self-regulatory, social responsibility of the alcohol producers, known for its ineffectiveness (Bakke and Endal 2010). In Nigeria, the case appears to be the same as the article will reveal.

Following the call for the drafting of strategies to control harmful alcohol in 2005, the actual draft of a ten-point strategy in 2008 and the adoption of 2010 WHO's resolution to implement policies, brewers in Nigeria adopted different SAs, in addition to their former tools, whose implicit aim, arguably, is to further distract policy makers from implementing alcohol policy. One of such is the intensified drink responsible campaign championed by Guinness Nigerian Plc., Nigerian breweries Plc. and International Centre for Alcohol Policies (ICAP). The campaign is mostly targeted at drivers by using posters to campaign in commercial motor parks and other public places (Vanguard, 2011).

The brewers and the ICAP are collaborating with one of the government agencies (Federal Road Safety Commission FRSC) in this campaign where drivers are advised to 'drink responsibly' instead of adopting don't drink if you will drive strategy which is the WHO's option. Brewers and the ICAP have spent millions of Naira (Guinness Nigeria, 2011) on this campaign and the reason may be via SA, to persuade the government that they are helping out to curb alcohol problems in Nigeria. This interpretation of strategy is supported by a concurrent campaign being run by the same breweries which encourages people to buy a drink and collect tokens which can be used to claim prizes such as more alcohol, money and cars (De Bruijn, 2011). The campaign does not recommend abstention for pregnant women or other vulnerable groups.

On the other hand, it is arguably a social responsibility campaign, and instead of affecting the brewers negatively, it may help them to achieve multiple goals because it generates multiple views and that may increase organizational positive image (Atkin et al., 2008) and higher sales. Behind the campaign for responsible drinking, lies the goal of silencing debate that may lead to policy to control harmful alcohol consumption stringently (Abramson in Atkin et al., 2008) or the initiation of policy that will not be effective (Holmila et al., 2011). The campaign is arguably aimed at frustrating the implementation of the numberfour strategy of the WHO 2010 resolution which is drink-driving policies and 
countermeasures (Poznyak, 2010). This, in part, is because it was initiated in 2010 being the year the WHA adopted the resolution to implement policies in countries that hitherto did not have alcohol policies (Vanguard, 2011). The other reason is because the policy makers may see the self-regulatory campaign as reasonable and good enough to deter misuse of which further resources need not be wasted in pursuit of further policies, especially in such countries with limited resources. This subtly adds to enhance the image of the brewers and can influence brand preference (Smith et al., 2006; Gordon et al., 2010). The message has been proved to likely 'create a positive image if the target audience perceives it as socially responsible' (Smith et al., 2006: 1) due to ambiguity of meaning. It is also part of the strategies that have been discovered to be ineffective in other countries (Anderson et al., 2009).

In Nigeria, there is no definition of responsible drinking by the government or Ministry of Health because there is no definition of standard drinks. There are no legal frameworks (policy) mandating alcoholic beverages to carry alcohol by volume (ABV) on labels, and there is no effective framework to deter minors from purchasing and consuming this substance (Oshodin, 1995). If responsible drinking (in units, volume/standard drink) is not defined by the government, then what is the basis for measuring responsible drinking in the campaign of the ICAP and brewers? This is SA because to have irresponsible drinking, what constitute responsible drinking must have been defined. For there to be responsible drinking for such people like pregnant women, they must be drinking in reality. But other countries including the UK warn individuals in such group not to drink at all (Farke 2011). This means arguably that it is an SA of brand promotion rather than the encouragement of abstinence.

There is also another fact not made obvious to Nigerian society and other populations: that the ICAP (who fronts this campaign and other targets of the advertisement campaigns) is an organization established and sponsored by global alcohol producers, including Guinness-Diageo the mother-company of the Guinness Nigeria to protect their interests (Casswell, 2008; McCreanor et al., 2002). This organization will never support stringent policy to regulate alcohol (Holmila et al., 2011) due to vested interest (Bakke and Endal, 2010). To show that such a marketing/image creation partnership is not to the benefit of the public, McCreanor et al. (2002: 183) posited that globally, 'the benefits to 
ICAP of partnership with the public have been made clear- respectability, credibility and the legitimation of ICAP's representation of industry interests in policy arenas'. This is the exact thing they have succeeded in doing in Nigeria.

Additionally, due to different progressive legislation in Western European and North American countries that has made it difficult for makers of adverse health products such as alcohol, tobacco, etc. to maintain high profit, they target Africa and Asia in their determination to recoup the profit margins that they lose in their home markets (Jernigan and Obot, 2006). They redeploy to Africa and Asia where the presence of weak states presided by irresponsible actors who disregard responsiveness by allowing them a field day to bribe their way around and make stupendous profit from the blood of the population.

Globally, alcohol industries use different SAs to achieve their aim of influencing policies that favour moderate drinking rather than abstention. In Australia, alcohol producers established Drinkwise with '\$5 million' (Miller et al., 2011: 1561) in 2005, in UK Drinkaware was formed by brewers while Alcohol 101 is in the USA (Piazza-Gardner and Barry, 2011). A very interesting position of these organizations sponsored by alcohol industries is that they often claim independence from the alcohol industry (Miller et al., 2011) whilst accepting their financial support. Globally, their modus operandi is similar, and one of such is: the campaign for responsible drinking and their reports on alcohol findings are bedevilled by inconsistencies (Miller et al., 2011; Jernigan, 2012). These moderating organisations usually send reports for peer review before publishing, but then don't change behaviour or culture in light of the comments from the peer reviewer which point to the initial weakness in the commissioning of their studies (Foxcroft, 2005). This is consistent with McCreanor et al's (2002: 181) assertion that:

Between 1995 and 1998, ICAP produced five reports. They are a vehicle that allows ICAP to promote its own ideas on alcohol policy issues while downplaying researchbased public health strategies. The first report encouraged drinking pointing out the benefits of moderate drinking and downplayed binge drinking.

In Nigeria, the role of the ICAP has not extended beyond prolonged seminars and campaigns that started in 2010. One thing that is not yet clear is why Guinness Diageo- the mother company of Guinness Nigeria waited until 2005 (the year the WHA raised alarm for policy to 
curb harmful use of alcohol) before initiating a global information strategy (Vanguard, 2011) and the ICAP and other brewers waited until 2010 (the year the WHO's resolution was adopted) to initiate and intensify their campaign for responsible drinking in Nigeria. This is despite the fact that Nigerian Breweries and Guinness have been in Nigeria since 1946 and 1962 respectively. It is likely that their recent campaigns were strategically managed to distract government attention from focusing on policies which are in line with the WHO's 2010 resolution. The campaign for responsible drinking by organizing seminars is also likely to delay call to action from the government or other stakeholders as Room (2005: 1803) comments:

...ICAP, an industry funded public relations group, defines its task as changing the debate about alcohol's place in the world by shifting the discussion from the commodity to behaviour, away from the traditional focus of policy discussion, which has been on the regulation of beverage alcohol.

Since the brewers/ICAP's campaign in collaboration with the FRSC began, the campaign has not ended to date, and no policy has been initiated. In fact, such partnership is what Hawks (2009) referred to as the lamb lying down with the lion. Just as, Eisenberg (1984) posited, organizations, that are facing tension or in a turbulent business environment use SA to achieve their goals, so brewers in Nigeria arguably are using the campaign for responsible drinking as a SA weapon to delay or entirely deter any move for a policy in Nigeria.

\section{Strategic Ambiguity of Advertisements}

Another aspect is the use of the SA by the brewers to advertise their products in Nigeria. For example, in the electronic media, the two-words, drink responsibly, is only briefly mentioned at the end of advertisement and is also placed inconspicuously on billboards. This arguably is SA to achieve multiple goals. Some of these goals are to create room for multiple interpretations among the public. Another goal may be to make the public to believe alcohol is good and thus increase sales. This is because ambiguous evidence such as 
'drink responsibly' makes consumers confused easily in that it generates multiple interpretations (Atkin et al., 2008) leading to what Eisenberg (1998) called flirting with meaning.

The producers and their marketers strategically situate principal cities with wide billboards portraying alcohol as good for health, success, joy, etc. (Obot and Ibanga, 2002) and inconspicuously place the two-words- drink responsibly at the bottom. They also print branded T-shirts as souvenirs and distribute them to the youths thus, making the youths walking billboards. This has implications because research has shown that it indirectly engages the youths in marketing and also makes other youths to endorse the brand seen on their peers' clothing (Stoolmiller et al., 2012). This advertising in both government and private media generate money for the government through tax and levy. This arguably is a method used to circumvent government policies in Nigeria.

In a country with over 250 officially recognized languages and low literacy level, such ambiguous words like 'drink responsibly' may remain ineffective. This is because, for the right decision to be made the decision maker needs to be properly informed. There are many Nigerians who do not understand English language. Therefore, this group may not be able to differentiate between responsible and irresponsible drink promotions, especially if safe drinking limits are not defined or specified by the government (due to lack of policy). This is another SA because no effort is made to translate responsible drinking into the local languages. As Eisenberg (1984) and Eisenberg and Witten (1987) posited, such clarity may be risky to the attainment of organizational multiple goals; the receivers are deliberately left with multiple interpretations and their actions will be based on how they interpret the message. One of such interpretations may be to regard the 'drink responsibly' as part of the overall advertisement because it does not come as a separate message (Agostinelli and Grube, 2002).

Among those who even understand the English language, it may be misunderstood to mean drinking makes you responsible. This is because it often ends their electronic media adverts after glamorizing drinking and as it is said that you reserve the best for last, people may understand it as telling them to drink because drinking is responsible. The message does not appear as a separate anti-drinking warning nor does it appear in the form of public 
service announcement like what obtains in some other countries (Agostinelli and Grube, 2002), and this is why it may not be efficacious. It is a pro-drinking campaign loaded with SA instead of an anti-drinking campaign which is most effective. Research findings have shown that warning messages with symbols achieve better results than the text alone (Argo and Main, 2004). Interestingly, the symbolic representation of the dangers of alcohol consumption are entirely absent in Nigeria. This is a choice that the brewers who fund the campaigns make. In line with the WHO Global Status Report on non-communicable Disease 2010, South Africa has proposed a total ban of alcohol advertisement (Parry et al., 2012) in order to check alcohol problems in that country. This is not same with the Nigerian government and their agencies. The latter is relying on self-regulation from alcohol producers.

As said, the drink responsibly warning message has been criticised because of its ambiguity, ineffectiveness and for playing the role of public relation advisor for the brewers (Smith et al., 2006) rather than as an anti-drinking campaign. Like Smith and colleagues argued, most of the adverts they surveyed in the USA, portrayed drinking being glamorized without showing the negative consequences of alcohol consumption. In Nigerian, the same effect can be seen in alcohol adverts (Obot and Ibanga, 2002). Attractive young males and females are employed as models and marketers, and advert clips are glamorised extensively with the 'drink responsibly' tag hurriedly ending it. The fact cannot be denied that the brewers are in business to make a profit, but economic interest should not overrule public health interest. This is because harmful alcohol use has multiple implications both for the individual and society (Fisher et al., 2007; Klingemann and Gmel, 2001; Djamba and Kimuna, 2008; Ayesu, 2011).

\section{Strategic Ambiguities of Job Creation, Poverty Alleviation and Social Responsibility}

One of the other parts of the use of the SA is the recent employment of local artistes to promote the brewers' products and the social event as against the foreign artistes they were using in the 1990s to early 2000s (Nigerian Breweries, 2012; Obot and Ibanga, 2002). For 
example, local musicians like Tuface Idibia, P-Square and many other popular musicians and footballers (who are mainly young and idolised) are employed to promote these social events (Nigerian Breweries, 2012). This is another SA because they might want to be seen as employers of labour or those who empower the youths as has been reported as one of their main strategies (Holmila at al., 2011). Therefore, those who have benefited from them may not want to initiate a move for a policy that may hinder their sources of wealth.

To attract the youth more, these two main brewers now have many other new youths' social events they sponsor. Some of these events are Star Trek, Star Quest, Star Game Show, Star Time to Shine, the Heineken Champions League Viewing Centre, Gulder Ultimate Search, Big Brother Africa, etc. (Nigerian Breweries, 2012; Guinness Nigeria, 2011). A unique feature of these events is that youthfulness is a criterion for registration and participation. The winners of some of these events go home with brand new cars, cash (in millions), and in most cases, a musical-record deal (Nigerian Breweries, 2012), and this is ambiguities of job creation and poverty alleviation.

Other events they have sponsored include the National Essay Competition for secondary school students, fashion show, the beauty pageant and sporting events on campuses (Obot and Ibanga, 2002). Though, the sponsorship of events had been in existence but may have become more intense since 2010 as information on one the leading brewers' website pointed out:

Our Corporate Social Responsibility is driven by a strategic vision to 'win with Nigeria'... Some of the initiatives taken along these lines in 2010 including the following:... The National Reading Competition which the company has been sponsoring since 2004 continued in 2010 as part of our youth empowerment programme... In 2010, one hundred and fifty million naira was approved to renovate and or donate classroom blocks... A school was provided with a borehole and generator... In 2010, we sustained our sponsorship of a public education and awareness programme to promote safety on our roads.... In conclusion, Corporate Social Responsibility is a strategic element of our operations... (Nigerian Breweries, 2012).

The Guinness Nigeria brewery has also sponsored National football team-Supper Eagles and the underlining intention in part may be to create an impression that Guinness is good for sports (De Bruijn, 2011). On the other hand, it may make the policy makers feel 
they are supportive of sports development in Nigeria; therefore, why regulating the availability of their products? It has been revealed that such sponsorships encourage brand preference and drinking (O'Brien et al., 2011). Researches have shown that sponsorship and advertising encourage young people to drink (Gordon et al., 2010) and create readiness to initiate drinking among people between 12-14 years (Gordon et al., 2011).

These events sponsored by brewers, are often held in different prominent cities, in Nigeria, and many are night events of which youths are admitted freely or with minimal payment (Nigerian Breweries, 2012). In these social events, young people, including those that are below 18 years attend. This is because, at present, Nigeria has no effective means of Identification due to the failed National Identity card Project during President Obasanjo's regime. For example, on May 25 2012, Nigerian Breweries, held the 'Real Deal Nite' at The NiteShift Coliseum located in Ikeja, Lagos to promote Legend Extra Stout and admission was totally free (Nigerian Breweries, 2012).

These events receive wide coverage by the media including the government's media, and some of them are staged in the government-owned arena such as the stadium and national theatre. The implication of this is that these producers are not just encouraging alcohol initiation, use and misuse, but are indirectly grooming future drinkers. This, in part, is because alcohol consumption is portrayed in a positive light and offered freely, thus creating the SA of seeing alcohol as always good. Another key implication is that the brewers use this measure to supplant government policy to restrict their activities because a huge sum of money is paid to government coffers as tax or levy for using government properties. So how can a government that receives levy make a policy that will reduce its revenue? Another salient point is that Nigerian Breweries and Guinness Nigeria own the third and thirteenth leading stocks in the Nigerian Stock market (Nigerian Breweries, 2012; Guinness Nigeria, 2011), and many top politicians in Nigeria own their stocks as shareholders. Therefore, policy to restrict the brewers' activities will not just affect the brewers but the stock owners, and Nigeria being as corrupt as it is (Smith, 2010), leaders are self-centred (Agbiboa, 2012) and may never formulate anti-alcohol policy.

Another part of the SA is that in these social events, different brands of their products are displayed strategically, and they use their senior staff to create a positive 
image of alcohol consumption. This arguably is SA created to achieve multiple goals for the brewers in Nigeria. This is because the use of alcohol is strategically portrayed as a sine qua non for success, thus, creating further ambiguity among the youths. In one of the National (secondary school) Essay Competition Awards, the chief executive officer of Nigerian Breweries who was the 'guest lecturer' promised that his company will support the essay competition with one million naira (about 6360 US dollars) annually for a five-year term and stylishly drank the Gulder beer from his company in the presence of teenagers as he delivered his lecture (Obot and Ibanga, 2002). In fact, Ola cited in Obot and Ibanga (2002: 7) described the situation this way: 'without saying it...the children must have taken away the impression that Gulder is good for you when you attain success-just the way (he) sipped the larger as he delivered his lecture'.

Another aspect of this SA lately is the regular promotions that encourage people to drink their products in order to win prizes such as electricity generating set, fridges, and even cars (Nigerian Breweries, 2012). The brewers 'conceal some of these prizes under the crown cork and advise consumers to uncover it and win any prize they discover' (De Bruijn, 2011: 37). Their redemption centres distribute the prizes and whoever has the winning seal on the crown cork (minors inclusive) receives the prizes. Apart from these promotions, they have also introduced raffle draws for money and cars and winners are drawn from different geo-political regions in the country (Nigerian Breweries, 2012).

This has a serious implication because research has revealed that giving away branded paraphernalia encourages harmful consumption of alcohol among those who directly received sponsorship or promotional materials (O'Brien, Kypri 2008). This may be one of the reasons industry-produced beer has become the most preferred alcoholic drink in Nigeria (Odejide, 2006). Arguably, this is SA because it goes for poverty alleviation and economic empowerment of the masses. For example, someone who won a car or cash by just buying a bottle of beer may not want to join in any debate for anti-alcohol policy. This is succeeding in Nigeria where the government encourages liberal trade policy.

The influence of these adverts, promotions, sponsorship of special events and other marketing strategies loaded with ambiguities have received little research attention in Nigeria. The only available data from the study conducted by the WHO Regional Office for 
Africa, revealed that alcohol advertisement and promotion are on the increase and that they have alarming influence on young people in Nigeria (Bruijn, 2011). In that study, a 14year old boy revealed that: 'if I don't see the stout ad on television, I feel bad' (De Bruijn, 2011: 37) and added that he will like to drink stout because he admires the advert he sees. In the same vein, another 14-year old girl indicated that she likes Star (a product from Nigerian Breweries) advertisement more than other adverts, "because you can win so many things, for example, free drinks' (De Bruijn, 2011: 37). This lends credence to the fact that alcohol advertisement affects youths' drinking behaviour (Saffer, 2002; Martin et al., 2002) and social benefits of drinking portrayed in adverts encourage young people to drink (Zwarun and Farrar, 2005).

\section{Conclusion}

The article has analysed the role of alcohol producers and their collaborator (ICAP) in aiding non-formulation and implementation of alcohol policies in Nigeria through SA. Just as, Eisenberg (1984) posited that organizations employ SA which is the use of unclear symbols, words and actions to achieve multiple goals, brewers in Nigeria use the SA of 'responsible drinking' campaign, adverts, promotion, sponsorship of events and 'strategic social responsibilities', especially since 2010 to hinder policy initiatives.

Though the paucity of published data on this debate may be evident in Nigeria, but myriad of evidence from the brewers' websites and others provided by renowned substance researchers outside Nigeria corroborate the fact that brewers often employ SA to either hinder policy initiatives or encourage ineffective policies globally. For example, in the New Zealand, McCreanor et al. (2002: 179) argued that: 'alcohol producers engage in a campaign to capture the hearts and minds of alcohol researchers and public health people, as part of a major effort to win the war of ideas that shape alcohol policy at national and international level'.

This is in keeping with what Jernigan (2012: 80) revealed about the ICAP in the USA, reporting that 'their strategies include producing scholarly publications with incomplete, distorted views of the science underlying alcohol policies; pressuring national and 
international governmental institutions; and encouraging collaboration of public health researchers with alcohol industry-funded organisations and researchers'. Because their campaign for responsible drinking is pro-drinking and detrimental to the public good, Anderson (2009: 256) in Europe concluded that '...alcohol industry should not be involved in educational programmes, because such involvement could actually lead to an increase in harm'. Another proof is their activities in sponsorship of education or conferences globally. For example, in the annual 'Conference of the State Liquor Administration held between 2024 June 2010 in the USA, $72.2 \%$ of the 187 conference attendees were from alcohol producers, importers, wholesalers, retailers, or their attorneys' (Mart, 2012: 259). Mart went on to show that $65 \%$ of the panellist came from 'alcohol industry' and he 'was the only attendee, and the only panellist, representing public health policy' (Mart, 2012: 259). Though this conference may not have taken place in Nigeria, but what can one expect to be the Communique of such a conference?

Therefore, to remedy the situation in Nigeria, it is expedient for the government to formulate and implement policies adopting the ten-point policy thrusts of the WHO's resolution 'strategies to reduce the harmful use of alcohol' (WHO, 2009; Poznyak, 2010) in Nigeria. Policy makers should reconsider their economic interests and rise to the global call for action against the rising menace of alcohol misuse and alcohol-related problems of which Nigeria is one of the leading contributors (Dumbili, 2013). There is a need to define what standard drink is, specify ABV for all the alcoholic beverages and mandate labels to carry it. The policy should encourage 'pictorial warnings' on the labels of cans and bottles. This will help non-literate consumers to understand what is being communicated. This in part is because noticeable pictorials and changing messages at intervals have resulted in behavioural change in Europe and the USA (Argo and Main, 2004; Hammond et al., 2004; Borland et al., 2009). On the other hand, vague information (such as 'drink responsibly') has been reported to hider safe drinking in the UK (Ritchie et al., 2009) and should be discouraged in Nigeria. Ban should be placed on advertising that portrays alcohol consumption as the only sources of vitality and pleasure. Sponsorships of special events by alcohol producers should also be discouraged. There is also need to ban night events these brewers sponsor because it is a strategic use of ambiguity, and initiate reorientation of the youths to change their wrong beliefs on alcohol-related benefits such as drinking to win 
prizes. In sum, if policy formulation keeps being neglected, alcohol-related problems may continue to rise in geometric progression in Nigeria.

\section{References}

Adewuya AO (2005) Validation of the alcohol use disorders identification test (audit) as a screening tool for alcohol-related problems among Nigerian university students. Alcohol and Alcoholism 40(6): 575-577.

Agbiboa DE (2012) Between corruption and development: The political economy of state robbery in Nigeria. Journal of Business Ethics 325(345): 1-21.

Agostinelli G and Grube J (2002) Alcohol counter-advertising and the media. Alcohol Research and Health 26(1): 15-21.

Ako T (2003) Strategic ambiguity of Chinese public space and private space: Ethnographic study of three Shanghai's middle schools under the socialist market economy. HKU Theses Online (HKUTO).

Alesina AF and Holden RT (2008) Ambiguity and extremism in elections. (No. 14143).National Bureau of Economic Research. (NBER Working Paper).

Anderson P (2009) Global alcohol policy and the alcohol industry. Current Opinion in Psychiatry 22(3): 253-257.

Anderson P Chisholm D and Fuhr D C (2009) Effectiveness and cost-effectiveness of policies and programmes to reduce the harm caused by alcohol. The Lancet 373(9682): 22342246.

Anumonye A Omoniwa $\mathrm{N}$ and Adaranijo $\mathrm{H}$ (1977) Excessive alcohol use and related problems in Nigeria. Drug and Alcohol Dependence 2(1): 23-30.

Argo JJ and Main KJ (2004) Meta-analyses of the effectiveness of warning labels. Journal of Public Policy and Marketing 23(2): 193-208. 
Atkin J McCardle M and Newell S (2008) The role of advertiser motives in consumer evaluations of 'responsibility' messages from the alcohol industry. Journal of Marketing Communications 14(4): 315-335.

Aworemi JR Abdul-Azeez IA and Olabode SO (2010) Analytical study of the causal factors of road traffic crashes in south-western Nigeria. Educational Research 1(4): 118-124.

Ayesu E (2011) Billboards, youth, unemployment and superstition in Mamfe-Akuapem, Ghana. Journal of Asian and African Studies 47(6): 634-651.

Bakke $\varnothing$ and Endal D (2010) Vested interests in addiction research and policy alcohol policies out of context: Drinks industry supplanting government role in alcohol policies in sub-Saharan Africa. Addiction 105(1): 22-28.

Bernheim BD and Whinston MD (1998) Incomplete contracts and strategic ambiguity. American Economic Review 88(4): 902-932.

Borland R Yong HH Wilson N Fong GT Hammond D Cummings KM and McNeill A (2009) How reactions to cigarette packet health warnings influence quitting: Findings from the ITC Four-Country survey. Addiction 104(4): 669-675.

Brisibe S Ordinioha B and Dienye PO (2012) Intersection between alcohol abuse and intimate Partner's violence in a rural ijaw community in Bayelsa state, south-south Nigeria. Journal of Interpersonal Violence 27(3): 513-522.

Burbank SB (2006) Aggregation on the couch: The strategic uses of ambiguity and hypocrisy. Columbia Law Review 106(7): 1924-1954.

Casswell S (2008) Alcohol industry and alcohol policy-the challenge ahead. Addiction 104(s1): 3-5.

Chick J (2011) The WHO global strategy to reduce the harmful use of alcohol. Alcohol and Alcoholism 46(3): 223-223.

Chikere EIC and Mayowa MO (2011) Prevalence and perceived health effect of alcohol use among male undergraduate students in Owerri, south-east Nigeria: A descriptive crosssectional study. BMC Public Health 11(1): 118.

Davenport S and Leitch S (2005) Circuits of power in practice: Strategic ambiguity as delegation of authority. Organization Studies 26(11): 1603-1623.

De Bruijn A (2011) Alcohol marketing practices in Africa-findings from Gambia, Ghana, Nigeria and Uganda: monitoring alcohol marketing in Africa MAMPA project. (MAMPA Project No. WM 274). Brazzaville: WHO Africa Regional Office. 
Djamba YK and Kimuna SR (2008) Intimate partner violence among married women in Kenya. Journal of Asian and African Studies 43(4): 457-469.

Dumbili E (2013) Changing Patterns of Alcohol Consumption in Nigeria: An Exploration of Responsible factors and Consequences. Medical Sociology Online 7(1): 22-33.

Eisenberg EM (1984) Ambiguity as strategy in organizational communication. Communications Monographs 51(3): 227-242.

Eisenberg EM (1998) Flirting with meaning. Journal of Language and Social Psychology 17(1): 97-108.

Eisenberg EM and Witten MG (1987) Reconsidering openness in organizational communication. Academy of Management Review 12(3): 418-426.

Farke W (2011) Health warning and responsibility messages on alcohol beverages- a review of practices in Europe. A report on Member States experiences which was written in scope of the EU Co-funded Project. ( No. 2011/03/WPS).

Fisher JC Bang H Kapiga SH (2007) The association between HIV infection and alcohol use: A systematic review and meta-analysis of African studies. Sexually Transmitted Diseases 34(11): 856-863.

Foxcroft D (2005) International centre for alcohol policies (ICAP)'s latest report on alcohol education: A flawed peer review process. Addiction 100(8): 1066-1068.

Giesbrecht N (2004) Science, public policy and the alcohol industry. From Science to Action? 100 Years Later-Alcohol Policies Revisited 5: 163-183.

Glennerster H (2012) Why was a wealth tax for the UK abandoned? Lessons for the policy process and tackling wealth inequality. Journal of Social Policy 41(2): 233-249.

Gordon R Harris F Mackintosh AM and Moodie C (2011) Assessing the cumulative impact of alcohol marketing on young people's drinking: Cross-sectional data findings. Addiction Research and Theory 19(1): 66-75.

Gordon R Mackintosh AM and Moodie C (2010) The impact of alcohol marketing on youth drinking behaviour: A two-stage cohort study. Alcohol and Alcoholism 45(5): 470-480.

Guinness Nigeria (2011) Corporate social responsibility: Sustainability and responsibility. Available at: http//:www.guinness-nigeria.com. Accessed 27 November 2012.

Gureje O Degenhardt L Olley B Uwakwe R Udofia O Wakil A and Anthony JC (2007) A descriptive epidemiology of substance use and substance use disorders in Nigeria during the early 21st century. Drug and Alcohol Dependence 91(1): 1-9. 
Hammond D McDonald PW Fong GT Brown KS and Cameron R (2004) The impact of cigarette warning labels and smoke-free bylaws on smoking cessation evidence from former smokers. Canadian Journal of Public Health 95(3): 201-204.

Hawks D (1992) Lying down with the lion: Co-operating with the alcohol industry? The 1991 Leonard Ball Oration. Drug and Alcohol Review 11(1): 51-58.

Holmila M Mäkelä P and Österberg E (2011) Alcohol policy is becoming a truly global issue. Nordic Studies on Alcohol and Drugs 28(1): 3-5.

Jernigan DH (2012) Global alcohol producers, science, and policy: The case of the international centre for alcohol policies. American Journal of Public Health 102(1): 8089.

Jernigan DH and Obot I S (2006) Thirsting for the African market. African Journal of Drug and Alcohol Studies 5(1): 57-70.

Klingemann H and Gmel G (2001) Mapping the social consequences of alcohol consumption. Dordrecht: Kluwer Academic Pub.

Mart SM (2012) Top priorities for alcohol regulators in the United States: Protecting public health or the alcohol industry? Addiction 107(2): 259-262.

Martin SE Snyder LB Hamilton M Fleming-Milici F Slater MD Stacy A Grube JW (2002) Alcohol advertising and youth. Alcoholism: Clinical and Experimental Research 26(6): 900-906.

McCreanor T Casswell S and Hill L (2002) ICAP and the perils of partnership. Addiction 95(2): 179-185.

Miller PG de Groot F McKenzie S and Droste N (2011) Vested interests in addiction research and policy. Alcohol industry use of social aspect public relations organizations against preventative health measures. Addiction 106(9): 1560-1567.

Miller PG Hall W West R Marsden J and Darke S (2010) A renewed call for action on alcohol policy. Addiction 105(5): 767-768.

Morgenstern M Isensee B Sargent J D and Hanewinkel R (2011) Exposure to alcohol advertising and teen drinking. Preventive Medicine 52(2): 146-151.

Myers G (1996) Strategic vagueness in academic writing. In E Ventola and A Mauranen (eds.): Academic Writing. Amsterdam: John Benjamins Publishing, pp. 3-18.

Nigerian Breweries (2012) Corporate social responsibilities. Available at: http//:www.nbplc.com/crs.html. Accessed 27 November 2012. 
Obot IS and Ibanga A (2002) Selling booze: Alcohol marketing in Nigeria. The Globe 2: 6-10.

Obot IS (2007) Nigeria: Alcohol and society today. Addiction 102(4): 519-522.

Obot IS (2012) Developing countries ignore drinking and driving problems at their own peril. Addiction 107(7): 1209-1210.

O'Brien KS and Kypri K (2008) Alcohol industry sponsorship and hazardous drinking among sports people. Addiction 103(12): 1961-1966.

O'Brien KS Miller PG Kolt GS Martens MP and Webber A (2011) Alcohol industry and nonalcohol industry sponsorship of sportspeople and drinking. Alcohol and Alcoholism 46(2): 210-213.

Oluwaniyi OO (2010) Oil and youth militancy in Nigeria's Niger Delta region. Journal of Asian and African Studies 45(3): 309-325.

Oshodin OG (1995) Nigeria. In Heath BD (ed.) International Handbook on Alcohol and Culture. Westport: Greenwood Press, pp. 213-223.

Parry C Burnhams NH and London L (2012) A total ban on alcohol advertising: Presenting the public health case. South African Medical Journal 102(7): 602-604.

Parry CDH (2010) Alcohol policy in South Africa: A review of policy development processes between 1994 and 2009. Addiction 105(8): 1340-1345.

Pedersen I (2002) Looking good on whose terms? Ambiguity in two Kellogg’s special ${ }^{\circledR}$ print advertisements. Social Semiotics 12(2): 169-181.

Piazza-Gardner A and Barry A (2011) A drink best not served: Conflicts of interests when the alcohol industry seeks to inform public health practice and policy. Journal of Clinical Research and Bioethics 4: 2.

Pitso J and Obot IS (2011) Botswana alcohol policy and the presidential levy controversy. Addiction 106(5): 898-905.

Poznyak V (2010) The WHO global strategy to reduce the harmful use of alcohol. (WHO National Counterparts for Alcohol Policy and AMPHORA No. WHA63. 13). Geneva: WHO.

Riedel F and Sass L (2011) The strategic use of ambiguity. (Working Paper no. 452): Institute of Mathematical Economics. Bielefeld University Germany.

Ritchie C Ritchie F and Ward R (2009) How can I drink safely? Perception versus the reality of alcohol consumption. The Service Industries Journal 29(10): 1397-1411.

Room R (2005) Drinking patterns as an ideology. Addiction 100(12): 1803-1804. 
Room R and Jernigan D (2000) The ambiguous role of alcohol in economic and social development. Addiction 95(12): 523-535.

Rotimi A (2005) Violence in the citadel: The menace of secret cults in the Nigerian Universities. Nordic Journal of African Studies 14(1): 79-98.

Saffer H (2002) Alcohol advertising and youth. Journal of Studies on Alcohol 63(2): 173-181.

Smith D (2010) Corruption, NGOs, and development in Nigeria. Third World Quarterly 31(2): 243-258.

Smith SW Atkin CK and Roznowski JA (2006) Are" drink responsibly" alcohol campaigns strategically ambiguous? Health Communication 20(1): 1-11.

Stoolmiller M Wills TA McClure AC Tanski SE Worth KA Gerrard M and Sargent JD (2012) Comparing media and family predictors of alcohol use: A cohort study of US adolescents. BMJ Open 2(1):2.

Toroyan T (2009) Global status report on road safety: Time for action. Geneva: WHO.

Ulmer RR and Sellnow TL (1997) Strategic ambiguity and the ethic of significant choice in the tobacco industry's crisis communication. Communication Studies 48(3): 215-233.

Ulph A and Ulph D (2001) Strategic innovation with complete and incomplete labour market contracts. The Scandinavian Journal of Economics 103(2): 265-282.

The Vanguard Newspaper (21 October 2011). Guinness Nigeria champions 'drink responsibly' campaign. Available at: http://www.vanguardngr.com/2011/10/guinnessnigeria-champions-'drink-responsibly\%E2\%80\%99-campaign/. Accessed 11 January 2013.

WHO (2005) Public health problems caused by harmful use of alcohol. Fifty-Eighth WHA. Geneva: WHO.

WHO (2009) Towards a global strategy to reduce harmful use of alcohol- discussion paper for regional technical consultation on harmful use of alcohol. Geneva: WHO.

WHO (2004) Global status report on Alcohol. Geneva: WHO.

Zwarun L and Farrar KM (2005) Doing what they say, saying what they mean: Self-regulatory compliance and depictions of drinking in alcohol commercials in televised sports. Mass Communication and Society 8(4): 347-371. 
